\title{
Development of Agglomeration Process to Utilize the Ferromanganese Fines in Steel Making Process
}

\author{
Veerendra SINGH and Vilas TATHAVADKER \\ R \& D Department, Tata Steel Ltd., Jamshedpur-831001, Jharkhand, India. E-mail: veerendra.singh@tatasteel.com.
}

(Received on April 28, 2010; accepted on September 9, 2010)

\begin{abstract}
An agglomeration process is developed to utilize FeMn fines of $<3 \mathrm{~mm}$ in LD steel making process. Different types of binders (sodium silicate, bentonite, acrylic resin and phenolic resin) were tried and found that phenolic resin is most suitable binder. Mixture of binder and fines was compacted in a cylindrical die and cured at $150^{\circ} \mathrm{C}$ for $1 \mathrm{~h}$. Briquettes of $30 \mathrm{~mm}$ diameter and $20 \mathrm{~mm}$ length were prepared and physical properties of the briquettes were tested. Tumbler index and shatter index of the briquettes were $\sim 95 \%$ and $>98 \%$, respectively. Compressive strength was $55 \mathrm{MPa}$ and density was $5200 \mathrm{~kg} / \mathrm{m}^{3}$. Usability of FeMn briquettes along with the FeMn lumps was evaluated in lab as well as in the plant. The results of lab test revealed tha FeMn briquettes dissolved faster than lumps. Improvement in Mn recovery was also observed in case of FeMn briquettes. Preliminary cost analysis indicated significant saving in alloying cost in steel making by use of briquettes made of low cost fines.
\end{abstract}

KEY WORDS: briquetting; steel making; ferroalloy and resin.

\section{Introduction}

More than $90 \%$ of the manganese produced worldwide is used by the steel industry. Mn alloys are added as a deoxidizing agent and as an additive to increase strength, elasticity and abrasion resistance of the steel. In steelmaking, overall consumption is in average 6 to $7 \mathrm{~kg}$ of pure manganese per ton of steel. Manganese is mainly added in the form of high carbon ferromanganese. Ferromanganese lumps of $10-80 \mathrm{~mm}$ are preferred in the steel making process to optimize the manganese recovery, deoxidation and losses during handling. Ferromanganese is made by carbothermic reduction of manganese ores in the electric arc furnace. Liquid hot metal is casted and crushed into $10-80 \mathrm{~mm}$ size. The fines generated during the sizing of metal cake can not be used in the LD steel making process. These fines get oxidized quickly and reduce the overall manganese recovery. ${ }^{1,2}$ The favorable size of ferromanganese is 3 to $20 \mathrm{~mm}$ to improve the dissolution characteristics. But small size means more surface area to transport undesirable gases and moisture. Small alloy size increases dust losses and incurs handling difficulties. ${ }^{3-6)}$

Agglomeration of ferromanganese fines can be the best method to utilize these fines. Various attempts have been made to agglomerate these fines using conventional binder like molasses, tar, resin, etc. ${ }^{6-10)}$ It was found that conventional binders are not suitable because these binders add $\mathrm{S}$ and $\mathrm{P}$ into the steel which is very much undesired. Whereas, use of hydrocarbon based binders was not technoeconoimc. Binder composition and physical strength of the agglomerate are two main constrains to develop a cost effective method. In the current study, a briquetting process has been developed to utilize these fines in steel making process. The suitability of the produced agglomerate was tested in the laboratory as well as in the plant. The developed method improves utilization of natural resources as well as minimizes the environmental pollution caused by steel industry.

\section{Experimental Studies}

\subsection{Characterization of Samples}

Samples of ferromanganese fines were collected from FAP, Joda, India. These were classified in three different size ranges $(>10 \mathrm{~m} ;-10+3 \mathrm{~mm} ;-3 \mathrm{~mm})$. Five (Mn, C, S, $\mathrm{P}$, and $\mathrm{Si}$ ) important constituents were analysized using ICP-OES (Spectro Analytical Instruments; Ciros) to find the chemical composition of prepared agglomerate. Particle shape and surface characteristics were also analyzed using scanning electron microscope to study the agglomeration behavior of fines.

\subsection{Agglomeration of Fines}

Agglomeration of metallic fines is a challenging subject. Selection of binder and strength of agglomerate are two most important process parameters. The binders should not add any unwanted ingredient like sulfur, phosphorus, nitrogen etc. in the steel and it should be cost effective. Molasses and other conventional organic binder were rejected because these binders contain sulfur and phosphorus. Sodium silicate and bentonite are the cheapest alternative of these binders and tried as per the conditions given in Table 1.

Acrylic resins are thermoplastic resin manufactured by 
the polymerization of various monomers such as acrylic acid, methacrylic acid, and esters of these acids. Phenol formaldehyde resin is the earliest commercial synthetic resin. It is formed from an elimination reaction of phenol with formaldehyde. Experimental studies were carried out using the resins to improve the quality of agglomerate. Resins were properly mixed $(5,8$ and $10 \%)$ in the ferromanganese fines and compacted at 15,45 and $70 \mathrm{MPa}(1,3$ and 5 ton) pressure to prepare suitable agglomerate.

Experimental work plan is given in Table 1 and Fig. 1. A sample of $<3 \mathrm{~mm}$ fines is collected and binder was mixed properly. Sixty to seventy gram mixture was compacted in cylindrical die of diameter $3 \mathrm{~cm}$ at different loads and compact was cured at different temperatures $\left(100^{\circ} \mathrm{C}\right.$ and $\left.150^{\circ} \mathrm{C}\right)$. Briquette density, compressive strength, tumbling index, abrasion index, shatter index and dissolution characteristics were studied.

\subsection{Lab Trials in Induction Furnace}

Twenty killograms of steel scrap is melted in a $25 \mathrm{~kg}$ induction furnace and $5 \mathrm{~kg}$ of ferromanganese lumps were added. Experiments were repeated for fines and briquettes to compare the results. Mixing behavior of the materials was observed. Slag and metal samples were collected. Manganese recovery was calculated. Figure 2 shows the lab scale setup to test the dissolution behavior of lumps, fines and briquettes in the liquid steel.

Table 1. Briquetting conditions.

\begin{tabular}{llll}
\hline Binder & $\%$ & Load (ton) & Curing Condition \\
\hline Sodium Silicate & $5,7.5 \& 10$ & $1 \& 5$ & $100 \mathrm{C}, 1$ hour \\
\hline Sodium Silicate + Bentonite & $5+2,7.5+2 \& 10+2$ & 1 & $100 \mathrm{C}, 1$ hour \\
\hline Acrylic Resin & $5,8 \& 10$ & $1 \& 3$ & $100 \mathrm{C}, 1$ hour \\
\hline Phenol formaldehyde Resin & $5,8 \& 10$ & $1 \& 5$ & $100 \& 150 \mathrm{C}, 1$ hour \\
\hline
\end{tabular}

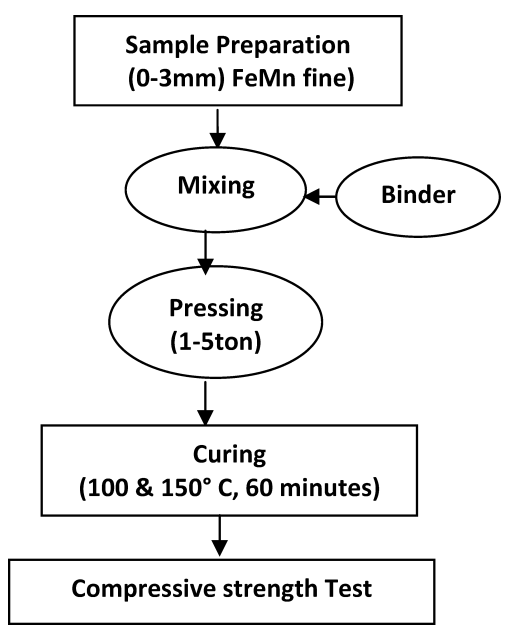

Fig. 1. Process methodology for binder selection.

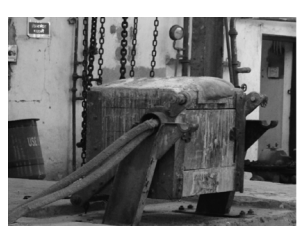

(a)

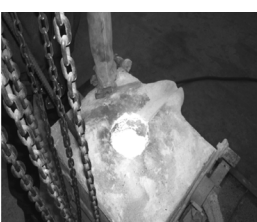

(b)

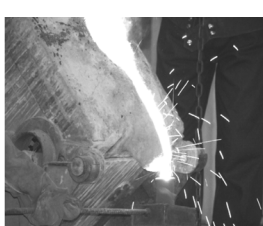

(c)
Fig. 2. Lab scale trials in induction furnace (a) induction furnace $(25 \mathrm{~kg}),(\mathrm{b})$ melting of scrap, (c) sample collection before and after the addition.

\section{Results and Discussion}

\subsection{Characterization Studies}

\subsubsection{Chemical Analysis}

Chemical analysis of various size fractions is given in Table 2. It was observed that $\mathrm{Si}$ is higher and $\mathrm{Mn}$ is lower in finer sizes than the lumps. Whereas, $\mathrm{P}, \mathrm{S}$ and $\mathrm{C}$ do not show any particular trend. Hence, the chemical composition of the fines is suitable for steel making process.

\subsubsection{Size and Shape Analysis}

Size analysis of ferromanganese fines $(0-10 \mathrm{~mm})$ samples were carried out and found that $\sim 70 \%$ fines are of 0 to $3 \mathrm{~mm}$ size (fines) and $30 \%$ are 3 to $10 \mathrm{~mm}$ size (chips). The fines of 0 to $3 \mathrm{~mm}$ contains $19.88,42.59$ and $37.54 \%$ of $1-3 \mathrm{~mm}, 0.5-1$ and $<0.5 \mathrm{~mm}$ fines, respectively. Particle Size and shape analysis is shown in Figs. 3 and 4. Finer particle sizes are preferred for briquetting but presence of significant amount of very angular particles makes the agglomeration process more challenging. Very angular particles enhance the mechanical interlocking but require high pressure compaction.

Table 2. Size and size wise chemical analysis of ferromanganese fines.

\begin{tabular}{ccrrrrc}
\hline Size Range & $\%$ & $\mathrm{C}$ & $\mathrm{Mn}$ & $\mathrm{S}$ & $\mathrm{P}$ & $\mathrm{Si}$ \\
\hline$>10 \mathrm{~mm}$ & 93 & 6 & $>68$ & 0.01 & 0.193 & 0.54 \\
\hline$-10,+3 \mathrm{~mm}$ & 2 & 6.75 & 67.30 & 0.01 & 0.175 & 1.72 \\
\hline$<3 \mathrm{~mm}^{\prime}$ & 5 & 6.7 & 66.90 & 0.01 & 0.188 & 1.33 \\
\hline
\end{tabular}

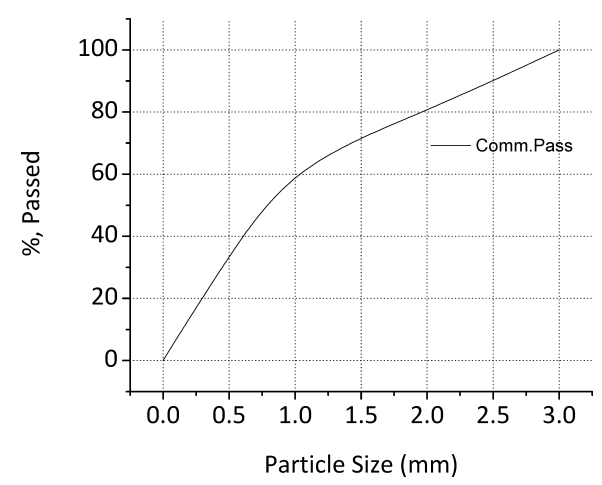

Fig. 3. Particle size analysis.

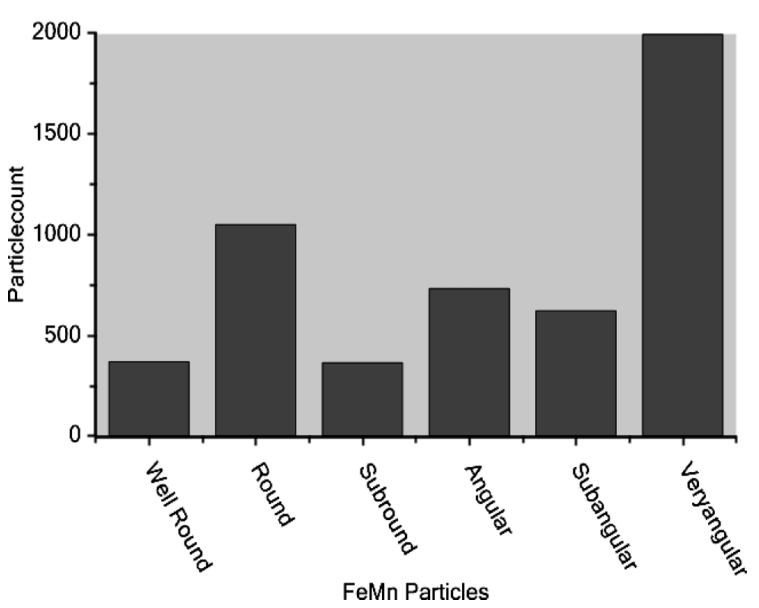

Fig. 4. Particle shape analysis. 


\subsubsection{SEM Analysis}

SEM samples of the lumps and briquettes were prepared to study the samples and find that fines are not oxidized. Some small slag inclusions were also seen in the briquetted samples. EDS spectra of different phases is shown in Fig. 5.

\subsection{Agglomeration Studies}

Metallic fines show different binding behavior than the conventional ore particles. Figure 6 shows surface of a manganese ore and ferromanganese metal particle. FeMn particle surface is very smooth and manganese ore particle shows suitable cracks and cleavages. The ore particles usually contain small crakes and cleavages which play important role in binder absorption and binding of the particles. Whereas, smooth surface reduces the wettability metal particles and it adversely affect the strength of liquid bonds.

\subsubsection{Conventional Binders}

The conventional binder (molasses, cement, lime etc.) which are used in agglomeration of ore fines can not keep the metallic particles together because of the difference in the particle characteristics. Hence, glassy or polymer bonds
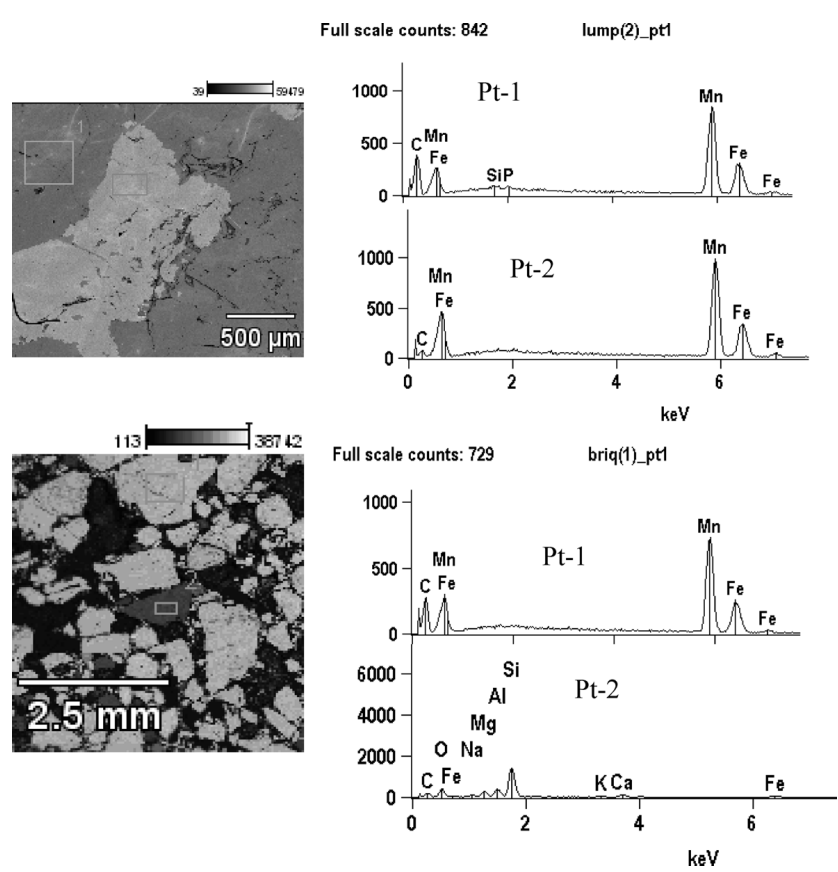

Fig. 5. SEM micrograph of Lumps (Pt1, high carbon phase; Pt2, low carbon phase) and briquettes (Pt1, high carbon phase; Pt2, slag particle).

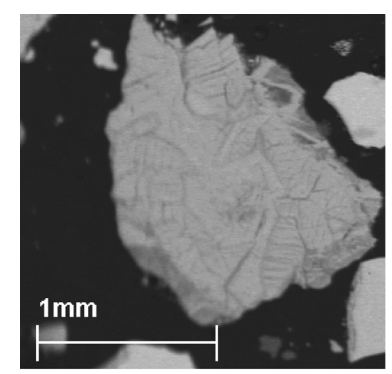

(a) Mn Ore Particle

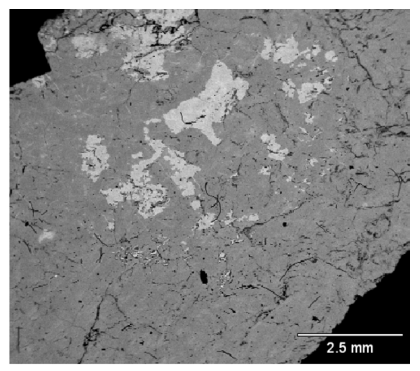

(b) FeMn Particle
Fig. 6. Surface roughness of Mn ore and FeMn metal particle. are required for this kind of materials. Three different combination of sodium silicate was tried and found that the prepared agglomerate does not attain the suitable compressive strength and it varies between 90 and $240 \mathrm{kgf} / \mathrm{sample}$. This can be increased by preparing agglomerate by machine compaction at 5 ton. The strength achieved by machine compaction was 700-1 150 kgf/sample. The small amount $(2 \%)$ of bentonite was also mixed with sodium silicate and found that it produce better results with $0-0.5 \mathrm{~mm}$ size range fines at one ton load compaction. The strength of the briquettes is not suitable for handling and presence of alkalis and silicon are a concern to use this into steel making process.

\subsubsection{Resins}

Acrylic and phenol based resin were used and found that acrylic resin produce an agglomerate of strength of 650 $1050 \mathrm{kgf} / \mathrm{sample}$ and 720 to $1100 \mathrm{kgf} / \mathrm{sample}$ by 1 ton and 5 ton compaction, respectively. This binder produces an agglomerate of brittle nature, which breaks in four or five bigger pieces. Thermosetting resin produces the best agglomerate with minimum compressive strength $1050 \mathrm{kgf} / \mathrm{sam}$ ple. Agglomerate strength vary between 1600-2000 kgf by machine compaction by 1 ton load. This strength increase further by 5 ton loading and it produces an agglomerate with $>2000 \mathrm{kgf}$ strength/sample. This binder produces good strength with manual compaction also and strength varies between 1050 to $1440 \mathrm{kgf} /$ sample for 5 and $10 \%$ binder content, respectively. A comparative analysis of maximum cold compressive strength achieved using different binders is given in Fig. 7 and it show that phenolic resin based agglomerate achieve maximum strength. Physical strength of cylindrical agglomerate depends on the length of the agglomerate and as the length increases the strength decreases. This was tested by producing different length agglomerate and finds that best suitable size in 15 to $20 \mathrm{~mm}$. Handling properties of theses briquettes were tested and shown in Table 3 for the briquettes produced with the most suitable binder combination. Apparent density of briquettes is $5200 \mathrm{~kg} / \mathrm{m}^{3}$ and cold compressive strength is $55 \mathrm{MPa}$. High compressive strength results into lower fine generation during handling of the briquettes. The briquettes achieve $95 \%$ and $98 \%$, tumble and shatter index, respectively. The physical charterstics of briquettes are acceptable to existing LD steel making process.

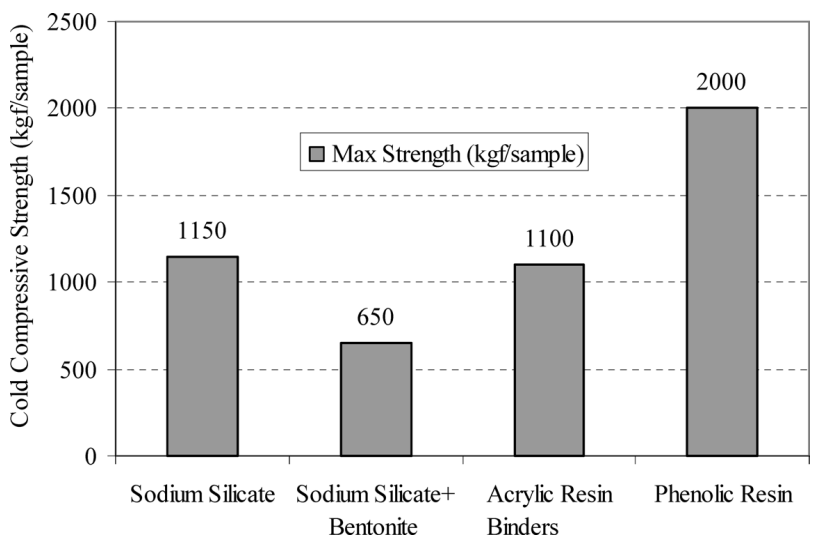

Fig. 7. Maximum cold compressive strength achieved by the briquettes using different binders. 
Table 3. Properties of briquettes.

\begin{tabular}{|l|l|}
\hline Properties & Briquette \\
\hline Size \& Shape & $\begin{array}{l}\text { Diameter : 30mm, L : } \\
\mathbf{2 0 m m}\end{array}$ \\
\hline Apparent Density & $\mathbf{5 2 0 0} \mathbf{~ k g} / \mathbf{m 3}$ \\
\hline Compressive Strength & $\mathbf{5 5 M p a}$ \\
\hline Tensile Strength (Load Applied in radial direction) & $\mathbf{1 5 M p a}$ \\
\hline Tumbler Index (Wt 15kg, rpm 200@25) & $\mathbf{9 5 \% ( > 6 . 3 m m )}$ \\
\hline Abrasion Index (Wt: 15kg, rpm 200@25) & $\mathbf{3 \%}(<\mathbf{0 . 5 m m})$ \\
\hline Shatter Index (Wt : 10 kg, No of Drops : 4, Height : 2m) & $98 \%(<5 \mathrm{~mm})$ \\
\hline
\end{tabular}

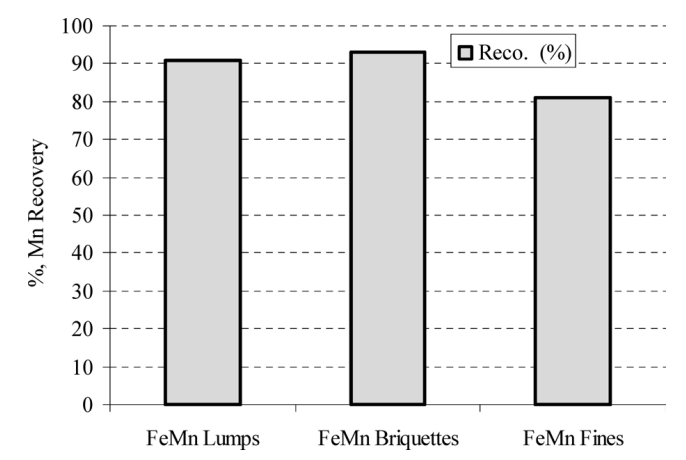

Fig. 8. Comparative analysis of Mn recovery from lumps, briquettes and fines.

\subsection{Product Validation}

Suitability of these briquettes was tested in the lab as well as in the plant. Mixing and other operational performance were observed during the lab scale induction furnace operation. It was observed that fines do not mix properly in the liquid steel and make bubbly structure on the top of the hot metal and also generate significant amount of slag. The slag generation was lowest for lumps and it was highest for fines. Manganese recovery is shown in Fig. 8. Mn recovery was lowest for the fines but it was similar for lumps and briquettes. Mn recovery was also observed for different types of briquettes tested for tumbling test. It was found that recovery reduces with the physical strength of briquettes and slag content increases. The best recovery was observed for the briquettes of $30 \mathrm{~mm}$ diameter and $20 \mathrm{~mm}$ thickness (weight: $65 \mathrm{~g}$ ) briquettes and same were used for the plant trial.

Plant trials were carried out using $500 \mathrm{~kg}$ of FeMn briquettes. The Plant adds 150 to $600 \mathrm{~kg}$ of ferromanganese in ladle of heat size 155 tons to produce different grade steels. 200 and $300 \mathrm{~kg}$ ferromanganese briquettes were added and operational efficiency was measured by Mn recovery. It was found the Mn recovery was 5 to $10 \%$ higher than the lumps. The improved dissolution characteristics can be an important cause of improved Mn recovery.

\section{Conclusion}

The ferromanganese fines are an inferior grade material which is generated in process of ferromanganese making. These fines can not be used in LD steel making process be-

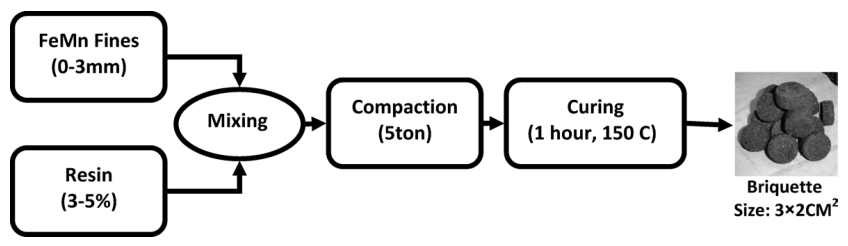

Fig. 9. Process flow sheet to agglomerate the FeMn fines.

cause of the smaller size hence an agglomeration process is developed for particles size enlargement by agglomeration. These fines can be agglomerated using resin as a binder followed by compaction and curing at $150^{\circ} \mathrm{C}$ temperature for $1 \mathrm{~h}$. Process flow sheet is shown in Fig. 9. The processing cost can be further reduced by optimizing the binder dosages and other processing conditions. The prepared agglomerates were tested in the lab as well as at plant and successful results were achieved. Handling and addition of ferroalloy fines into foundry add significant amount of metallic dust into environment and the proposed process can reduce this environmental pollution. A one million ton annual capacity steel plant can consume $3-5 \mathrm{k}$ ton high carbon ferromanganese depending on the product grade. In the current market scenario the proposed process can save $\$ 200-250 /$ ton including the improved process performance and cost difference between lumps and agglomerate, which will result into saving of $\$ 5$ million/annum.

\section{Acknowledgement}

The authors express their sincere thanks to Dr. D. Bhattachrjee, Director, RD\&T, TATA Steel, Mr. Dinesh Shastri, EIC, FAMD and Mr. D. Das Chief LD\#1, Tata Steel for their keen interest and guidance in the present study.

\section{REFERENCES}

1) K. D. Peaslee, D. S. Webber, S. Lekakh and B. Randall: 58th SFSA Technical and Operating Conf., Steel Founders' Society of America, IL, USA, (2005), 4.1.

2) P. G. Sismanis and S. A. Argyropoulos: Proc. of the 69th Steelmaking Conf., Vol. 69, Iron \& Steel Society, Warrendale, PA, (1986), 315.

3) Y. Lee, H Berg, B. Jensen and J. Sandberg: Iron Steel Soc., 54 (1996), 237.

4) M. Tanaka, M. Mazumdar and R. I. L. Guthrie: Metall. Trans. B, 24B (1993), No. 4, 639.

5) H. Berg, H. Laux, S. T. Johansen and O. S. Klevan: Ironmaking Steelmaking, 26 (1999), No. 2, 127.

6) V Singh, S. M. Rao, B. D. Nanda and D. Srinivas: International Patent Application No. 2009-PCT/IN2009/000532, (2009).

7) V. L. Calbert: United States Patent 1946-2405278, (1946).

8) R. Saunders, P. Earle and L. Richard: United States Patent 19602935397, (1960).

9) L. Robert and Ranke: United States Patent 1975-3898076, (1975).

10) J. P. Beukes, J. Nell and S. D. McCullough: South Africa Patent: 2001-4091.

11) A. Ramu, P. K. Banerjee and B. R. Choudhury: Unpublished Report, R\&D Tata Steel, India, R\&D-INV-011-96-1-13-97(1997). 